\title{
Microencapsulation of Sideritis raeseri Boiss. \& Heldr. subsp. raeseri Extract Using Spray Drying with Maltodextrin and Whey Protein
}

\author{
Jelena Vladić1, Nataša Nastić1, Teodora Janković², Katarina Šavikin², Nebojša Menković

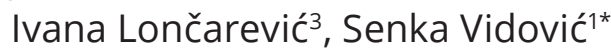

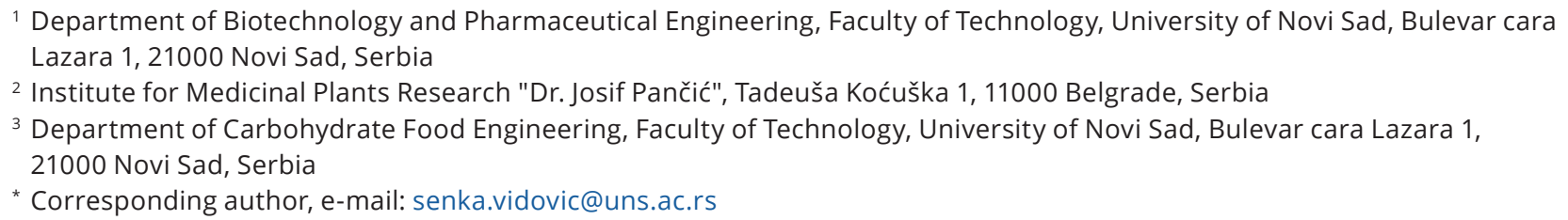

Received: 09 August 2021, Accepted: 08 November 2021, Published online: 11 February 2022

\begin{abstract}
Multiple medical properties and beneficial influence on health attributed to the aerial parts of Sideritis raeseri Boiss. \& Heldr. subsp. raeseri indicated the need for further investigation. S. raeseri extracts were subjected to microencapsulation by the spray drying process in order to disperse and preserve unstable active compounds within a protective matrix. Two inlet air temperatures (120 and $\left.140{ }^{\circ} \mathrm{C}\right)$ were applied for the encapsulation of S. raeseri extract in a matrix composed of maltodextrin (10, 20, and 40\%) or whey protein (40\%). The effects of spray drying on physico-chemical properties, contents of total phenols and flavonoids, as well as of individual flavonoid glycosides of the obtained powders were determined. The $40 \%$ whey protein treatment increased bulk density $(238.46 \mathrm{mg} / \mathrm{mL}) \mathrm{while}$ it decreased hygroscopicity (14.27\%). In addition, the high maltodextrin concentration of the S. raeseri powder resulted in the highest process efficiency (63.46\%), the highest water solubility index (86.40\%), and the lowest water absorption index (5.71\%). Moreover, powders produced without maltodextrin were characterized by greater content of flavonoid glycosides. Overall, the results suggested that S. raeseri powders produced using spray-dried technique under adequate conditions could be considered as a novel functional and pharmaceutical ingredient.
\end{abstract}

Keywords

Sideritis raeseri, spray drying, maltodextrin, whey protein, flavonoids

\section{Introduction}

The wide use and significant role of Sideritis species as a traditional medical remedy has been reported in several ethnobotanical and pharmacological studies [1-3]. The genus Sideritis is widely spread and represented by more than 150 species, commonly collected and locally used mainly in Mediterranean Europe and Northern Africa, the Balkans, and the Iberian Peninsula [4, 5]. Sideritis raeseri Boiss. \& Heldr. subsp. raeseri is a subalpine/alpine perennial herb and it is consumed in the form of a decoction and infusion, for the treatment of sinus congestion, gastrointestinal disorders, sore throats, flu, common cold, pain, and mild anxiety [1]. The occurrence of phenylpropanoids, flavonoids, hydroxycynnamic acid derivatives and terpenoids in $S$. raeseri has been related to its antioxidant, anti-inflammatory, hypotensive, vasorelaxant, cardiodepressant, and spasmolytic activities [2, 6-9].

Due to health trends and social changes, the commercial importance and development of herbal medicines, in particular food supplements, derived from plants with therapeutic potential such as $S$. raeseri, are forecasted to increase in the global market. In order to provide the protection and stabilization of extractable compounds with health importance, the microencapsulation process has been widely used. Spray drying, spray-cooling, extrusion, centrifugal extrusion, freeze drying, and molecular inclusion are methods used to perform the encapsulation technology. According to the available literature, spray drying is a common method 
because of its low cost, short drying time, easy scale-up, good quality of microparticles, reproducibility, and readily available equipment [10, 11]. Nadeem et al. [12] successfully encapsulated S. stricta water extracts using different hydrocolloid carriers. Dontas et al. [13] produced spray-dried S. euboea powders with higher concentration and stability of active compounds. To the best of our knowledge, there is no reported information on the spray drying microencapsulation of active compounds from S. raeseri Boiss. \& Heldr. subsp. raeseri commonly used in Greece, Albania, Serbia, and Northern Macedonia.

Therefore, the present study was undertaken in order to investigate the influence of different carrier materials and spray drying conditions on $S$. raeseri extract with respect to encapsulation efficiency, moisture content, hygroscopicity, bulk density, water solubility, particle size distribution, as well as the content of total phenols, total flavonoids, and individual flavonoid glycosides.

\section{Experimental}

\subsection{Chemicals}

Methanol (J. T. Baker, Netherlands) and acetonitrile (Merck, Germany) were of HPLC grade. Ultrapure water was prepared using a Milli-Q purification system (Millipore, France). Folin-Ciocalteu reagent, maltodextrin, gallic acid, and catechin were purchased from Merck (Germany). Whey protein was purchased from BioTechUSA (USA).

\subsection{Plant material and extraction}

S. raeseri Boiss. \& Heldr. subsp. raeseri was purchased in 2018 from Agroherbal, Tirana, Albania by the Institute for Medicinal Plants Research "Dr. Josif Pančić", Belgrade, Serbia.

Liquid extract of $S$. raeseri was obtained using percolation with $50 \%$ ethanol as a solvent. The plant material/ solvent ratio was 1:5. Extraction was carried out at room temperature.

\subsection{Spray drying process}

The carrier materials, maltodextrin (DE19.7; 10, 20 and $40 \%$ ), and whey protein (10, 20 and $40 \%$ ) were used in the liquid feed, compared to the amount of total solids (w/w). Total solids content amounted to $29.06 \pm 0.289 \mathrm{mg} \mathrm{mL}$. The powders that were obtained by drying with 10 and 20\% whey protein had inadequate properties with respect to stickiness and remaining in the drying chamber. Therefore, the work was continued only with the powder obtained with the $40 \%$ whey protein while lower concentrations applied were characterized as inadequate for drying of $S$. raeseri.
Drying of the extract without the addition of a carrier material was performed in order to characterize the dry extract. Carrier materials were dissolved in distilled water. These carrier solutions were added to the prepared extract and mixed continuously with a magnetic stirrer at a temperature of $30^{\circ} \mathrm{C}$. Such feeds were pumped into the spray drying system. The prepared liquid feed was spray dried using an Anhydro laboratory spray dryer (APV Anhydro AS, Denmark). A peristaltic pump was used to pump the feed into the dryer. The process inlet temperatures were 120 and $140{ }^{\circ} \mathrm{C}$, while outlet air temperatures were $70 \pm 4$ and $80 \pm 4{ }^{\circ} \mathrm{C}$. The drying process was carried out at a constant pressure of 3 bar. During the process, it was possible to adjust the pressure with the compressor and the inlet air temperature. Atomizer speed ranged from 20000 to $21000 \mathrm{rpm}$. The obtained powder was separated from air by a cyclone. The efficiency of powder production (expressed as the weight percentage) was determined gravimetrically as the ratio of the mass of the powder obtained after spray drying and mass of total solids measured in the liquid feed. All spray drying processes were carried out in duplicate.

\subsection{Moisture content}

Moisture content was determined according to the standard procedure described in the official Pharmacopeia (Ph. Jug. IV), by drying a sample at $105^{\circ} \mathrm{C}$ until constant mass. All measurements were carried out in triplicates.

\subsection{Hygroscopicity}

Hygroscopicity measurements were performed using the method described by Vladić et al. [14]. Hygroscopicity was expressed as a gram of absorbed water per $100 \mathrm{~g}$ of dry extract powder. All measurements were carried out in triplicates.

\subsection{Bulk density}

Bulk density was measured by determining the volume occupied by the dry extract mass. Powder $(1 \mathrm{~g})$ was freely added into a $20 \mathrm{~mL}$ graduated glass cylinder and exposed to vibration for $2 \mathrm{~min}$. Bulk density was calculated from the difference of the empty glass cylinder and the mass of the glass cylinder with powder and expressed as $\mathrm{mg}$ of powder per mL. All measurements were carried out in triplicates.

\subsection{Water solubility index and water absorption index}

Determination of the water solubility index (WSI) and water absorption index (WAI) was achieved according to a previously described method [15]. WSI was calculated as the ratio of the mass of dried supernatant and the mass of the dry sample. WAI was calculated as the mass of solid 
pellets remaining after the elimination of the supernatant divided by the mass of the dry sample. All measurements were carried out in triplicates.

\subsection{Particle size distribution}

The particle size and size distribution were determined by a laser diffraction size analyzer Mastersizer 2000 (Malvern Instruments, Worcestershire, UK) equipped with the Scirocco2000 dispersion unit. The samples were added at ambient temperature until an adequate obscuration was obtained (5-10\%). The size distribution was quantified as the relative volume of particles in size bands presented as size distribution curves using the Mastersizer 2000 software. All measurements were carried out in triplicates. The particle size, $d(v, 0.1)$ (size of the particles for which $10 \%$ of the sample volume contains particles smaller than $d(v, 0.1)), d(v, 0.5)$ (size of the particles for which $50 \%$ of the sample volume contains particles smaller than $\mathrm{d}(\mathrm{v}, 0.5))$, $d(v, 0.9)$ (size of the particles for which $90 \%$ of the sample volume contains particles smaller than $d(\mathrm{v}, 0.9))$, and $\mathrm{D}[4,3]$ (size that represents the average mass-volume diameter) were used as characterization parameters.

\subsection{Total phenolic and total flavonoid content}

Total phenolic content (TPC) was determined by a colorimetric assay based on a modified procedure initially described by Kähkönen et al. [16]. Absorbance was measured at 750 nm (6300 Spectrophotometer, Jenway, Dunmow, UK). The calibration curve was defined using gallic acid as a standard and the results were expressed as $\mathrm{mg}$ of gallic acid equivalent per $\mathrm{g}$ of powder (mg GAE/g). All experiments were performed in three replicates and the results are expressed as mean values. Total flavonoid content (TFC) was determined using aluminum chloride colorimetric assay [17]. Absorbance was measured at $510 \mathrm{~nm}$. The calibration curve was defined using catechin as a standard and the results are expressed as $\mathrm{mg}$ of catechin equivalents per $\mathrm{g}$ of powder (mg CE/g). All experiments were performed in triplicate and the results are expressed as mean values.

\subsection{HPLC analysis}

High performance liquid chromatography (HPLC) analyses of $S$. raeseri powders were performed using an Agilent series $1200 \mathrm{RR}$ coupled to a DAD detector according to a method previously described by Pljevljakušić et al. [18]. The stationary phase used for the separation of compounds was a reversed phase LiChrospher RP-18 analytical column $(250 \times 4 \mathrm{~mm}$ i.d., particle size $5 \mu \mathrm{m})$. The mobile phase was $1 \% 0.1 \mathrm{~N} \mathrm{H}_{3} \mathrm{PO}_{4}$ formic acid in water as eluent $\mathrm{A}$ and acetonitrile as eluent $\mathrm{B}$. The solvent gradient changed according to the following conditions: $0-5 \mathrm{~min}, 90-80 \% \mathrm{~A}$; 5-10 $\mathrm{min}, 90 \% \mathrm{~A} ; 10-20 \mathrm{~min}, 80-70 \% \mathrm{~A} ; 20-30 \mathrm{~min}$, 70-30\% A, and 30-35 min, 30-0\% A. Detection and quantification were performed at 280 and $330 \mathrm{~nm}$. Four flavonoids, previously isolated in the laboratory at the Institute for Medicinal Plants Research "Dr. Josif Pančić", were used for quantification: isoscutellarein 7-O-[6"'-Oacetyl- $\beta$-D-allopyranosyl $\quad(1 \rightarrow 2)]-\beta$-D-glucopyranoside (ISC 1), 4'-O-methylisoscutellarein-7-O-[6"'-O-acetyl- 3 D-allopyranosyl $(1 \rightarrow 2)]-\beta-D$-glucopyranoside (ISC 2), 4'-O-methylhypolaetin-7-O-[6"'-O-acetyl- $\beta$-D-allopyranosyl $(1 \rightarrow 2)]-\beta-D-$ glucopyranoside (HYP 1) and 4'-Omethylhypolaetin-7-O-[6"'-Oacetyl- $\beta$-D-allopyranosyl $(1 \rightarrow 2)]-6$ "'-O-acetyl- $\beta$-D-glucopyranoside (HYP 2). Quantification of flavonoids identified in the samples was performed using corresponding calibration curves.

\subsection{Statistical analysis}

All analyses were carried out in triplicate and the results were expressed as means \pm standard deviation (SD). Mean values were considered significantly different at $p<0.05$ confidence level, after the performance of the one-way ANOVA statistical analysis followed by Tukey's HSD post hoc test.

\section{Results and discussion}

\subsection{Process efficiency}

Superior quality powders (optimum recovery, absence of stickiness, absence of wall deposition phenomenon) are desired on the industrial processing level. Therefore, it is essential to consider the factors influencing the final product properties. The efficiency of the spray drying process was determined through the evaluation of the recovery of $S$. raeseri powders (Table 1).

The powder recovery obtained by the spray drying process presented values in the range of 31.01-62.79\% which is higher than the recoveries of $S$. stricta powder obtained at different inlet air temperature, type of carrier material and its concentration by Şahin-Nadeem et al. [19]. In the case of $S$. raeseri powders without the addition of MD and with the addition of MD in concentration of $10 \%$, the stickiness of the herbal extract on the spray dryer walls took place. Low molecular weight compounds such as sucrose, fructose, and glucose can cause the powder to be retained on the spray dryer walls resulting in technical issues and lower process efficiency. For these reasons, carrier materials of higher molecular weight were used. 
Table 1 Process efficiency, moisture content and hygroscopicity of $S$. raeseri powders

\begin{tabular}{|c|c|c|c|c|c|c|c|}
\hline \multirow{3}{*}{ Carrier } & \multirow{3}{*}{$\begin{array}{c}\text { Carrier } \\
\text { concentration }\end{array}$} & \multicolumn{6}{|c|}{ Temperature $\left({ }^{\circ} \mathrm{C}\right)$} \\
\hline & & 120 & 140 & 120 & 140 & 120 & 140 \\
\hline & & \multicolumn{2}{|c|}{ Process efficacy $(\%)$} & \multicolumn{2}{|c|}{ Moisture content $(\%)$} & \multicolumn{2}{|c|}{ Hygroscopicity (\%) } \\
\hline \multirow{4}{*}{ Maltodextrin } & 0 & 42.12 & 31.01 & $3.42 \pm 0.21^{\mathrm{a} 1}$ & $2.75 \pm 0.28^{\mathrm{a} 2}$ & $17.40 \pm 0.12^{\mathrm{a}}$ & $16.92 \pm 0.33^{\mathrm{a}}$ \\
\hline & 10 & 41.71 & 39.48 & $3.93 \pm 0.12^{\mathrm{a}}$ & $3.95 \pm 0.63^{\mathrm{abcd}}$ & $15.24 \pm 0.33^{b}$ & $15.49 \pm 0.02^{\mathrm{b}}$ \\
\hline & 20 & 44.27 & 55.51 & $4.98 \pm 0.63^{b}$ & $4.27 \pm 0.44^{c}$ & $15.23 \pm 0.81^{\mathrm{bcl}}$ & $16.66 \pm 0.26^{\mathrm{ac} 2}$ \\
\hline & 40 & 58.91 & 63.46 & $5.01 \pm 0.35^{\mathrm{b}}$ & $4.23 \pm 0.48^{\mathrm{cd}}$ & $16.02 \pm 0.11^{\mathrm{bcd}}$ & $15.93 \pm 0.3^{1 \mathrm{bd}}$ \\
\hline Whey protein & 40 & 62.79 & 61.58 & $6.16 \pm 0.41^{\mathrm{c}}$ & $5.52 \pm 0.65^{\mathrm{cde}}$ & $14.27 \pm 0.08^{\mathrm{bcel}}$ & $15.20 \pm 0.22^{\mathrm{be} 2}$ \\
\hline
\end{tabular}

Means followed by different letters ( $a, b, c, d)$ in a column are different from each other i.e., there is a significant and measurable difference between powders obtained with different carriers and concentrations at $p<0.05$ (the probability of obtaining that difference by chance is very small).

This statistical parameter can therefore confirm the existence of powders with different competitive ability within the same property and process temperature. Means followed by the same letters within a column are not significantly different.

Means followed by different numbers $(1,2)$ in a row are different from each other, i.e., there is a significant difference between powders in terms of different properties and process temperature at $p<0.05$. This statistical parameter can therefore confirm the existence of powders with different competitive ability within the same carrier concentration. Means followed by the same number within a row are not significantly different.

Various carrier materials were also utilized to prevent possible formation of agglomerates and crystallization during further processing of powders as well as to prolong shelf life and stability [20]. Using 10\% MD as a carrier material, the content of active compounds retained in the encapsulated sample corresponded to $41.71 \%\left(120^{\circ} \mathrm{C}\right)$ and $39.48 \%\left(140{ }^{\circ} \mathrm{C}\right)$. Better results were achieved when using $20 \% \mathrm{MD}$ as a carrier material with $44.27 \%\left(120^{\circ} \mathrm{C}\right)$ and $55.51 \%\left(140^{\circ} \mathrm{C}\right)$ efficacy of the process. The efficiency of the spray drying process was the highest for the $40 \% \mathrm{MD}$ powder $\left(58.91 \%\left(120^{\circ} \mathrm{C}\right)\right.$ and $\left.63.46 \%\left(140{ }^{\circ} \mathrm{C}\right)\right)$. A similar observation was confirmed during spray drying of chokeberry [21] and garlic [22]. Furthermore, whey protein (WP) encapsulates' yield was higher (62.79\%) in comparison to other powder yields at $120{ }^{\circ} \mathrm{C}$. A slightly lower recovery of powder $(61.58 \%)$ was observed when using higher temperature, but even in that case, it was two-fold higher than the values observed for the powder without the addition of a carrier. According to Bhandari et al. [23], recovery of powders higher than $50 \%$ is regarded as a criterion for an efficient spray drying process in laboratory dryers together with the absence of stickiness and wall deposition phenomena.

Considering all results, the process of $S$. raeseri powders production can be considered efficient when using $40 \% \mathrm{MD}$ and $40 \% \mathrm{WP}$ at both process temperatures. In addition, MD in concentration of $20 \%$ in the liquid feed was found to be favorable for the process efficiency when carried out at a temperature of $140{ }^{\circ} \mathrm{C}$, but also for other powder properties such as moisture content less than $5 \%$ and high hygroscopicity (Table 1).

\subsection{Moisture content}

Moisture content less than 5\% indicated that the obtained powder is stable and suitable to be included as an additive in functional foods, dietary supplements, and pharmaceuticals. According to Sun et al. [24], lower moisture content also reduced lipid oxidation, enzyme activity, and microbial growth. All spray-dried MD powders of $S$. raeseri had moisture contents lower than 5\% (Table 1). The powders obtained without a carrier material had the lowest moisture content $\left(3.42 \%\right.$ at $120{ }^{\circ} \mathrm{C}$ and $2.75 \%$ at $\left.140{ }^{\circ} \mathrm{C}\right)$. Moisture content increased with the addition of MD which was the highest with $40 \% \mathrm{MD}$ at $120{ }^{\circ} \mathrm{C}(5.01 \%)$. The microcapsules obtained with WP had a slightly higher moisture content in comparison to MD powders probably due to the greater water holding capacity of proteins [25]. A higher moisture content of protein-based spray-dried powders has been reported in a study by Jokić et al. [26]. Regardless of the carrier material, higher inlet temperature resulted in lower moisture contents of $S$. raeseri powders, but it was statistically insignificant $(p>0.05)$ in comparison to lower temperatures. Similar findings were observed by Ståhl et al. [27] and Chegini and Ghobadian [28] which can be explained by the fact that the rise in temperature increases the rate of heat transfer to the particle and acts as a driving force for water evaporation [29].

\subsection{Hygroscopicity}

According to the hygroscopicity classification of GEA Niro Research Laboratory [30], powders were classified as non-hygroscopic $(<10 \%)$, slightly hygroscopic (10-15\%), hygroscopic (15-20\%), very hygroscopic (20.1-25\%), and strongly hygroscopic $(>25 \%)$. It is highly desirable to keep 
the hygroscopicity as low as possible because lower hygroscopicity will result in greater stability of the final product. The hygroscopicity of the $S$. raeseri powders ranged from 14.27 to $17.40 \%$ (Table 1 ). The highest hygroscopicity was determined for the encapsulated extract obtained without the addition of a carrier (Table 1). Slightly lower hygroscopicity of $S$. raeseri powders was obtained with MD in concentrations of 10,20 , and $40 \%$ due to reduced viscosity of MD at high concentrations [31]. However, Quek et al. [32] reported that powder obtained with too high MD concentrations were of lower quality because the concentration of active compounds encapsulated in powder was diluted. In our study, slightly hygroscopic powder was obtained using WP as a carrier material. An inverse correlation between hygroscopicity and moisture content was observed probably due to the greater water concentration gradient between the powder and the drying air [33]. Bazaria and Kumar [34] revealed that the moisture content of beetroot powder obtained with WP increased with a decreased percentage of hygroscopicity and inlet air temperature. In this study, the hygroscopicity of the powder was not significantly affected by the inlet air temperature.

\subsection{Bulk density}

High bulk density of powdered products is an important property in the production of dietary supplements, as well as in the production of various pharmaceutical forms such as capsules and tablets. The bulk density of S. raeseri powders ranged from 139.9 to $238.5 \mathrm{mg} / \mathrm{mL}$. According to ANOVA, the inlet air temperature and carrier material had exerted a significant influence on bulk density at $p<0.05$ confidence level. A higher concentration of MD corresponded directly to a higher bulk density due to the lower particle size of microcapsules [35]. The highest bulk density of powder was obtained by WP at $140{ }^{\circ} \mathrm{C}(238.46 \mathrm{mg} / \mathrm{mL})$. Suitable proteins lodgement among particles occupying less space might be the reason for such behavior [36]. WP and 40\% MD powder had similar bulk densities (200.78 and $204.29 \mathrm{mg} / \mathrm{mL}$ at $120^{\circ} \mathrm{C}$, respectively). Also, it was observed that powders without a carrier presented higher bulk densities $(162.81 \mathrm{mg} / \mathrm{mL}$ at $120^{\circ} \mathrm{C}$ and $201.04 \mathrm{mg} / \mathrm{mL}$ at $140{ }^{\circ} \mathrm{C}$ ) than the encapsulated powders with 10 and $20 \%$ MD. Furthermore, higher inlet temperature caused bulk density augmentation which was confirmed by Manickavasagan et al. [37]. Conversely, bulk density reduction was observed in the case of 20 and $40 \%$ MD. A temperature increase led to lower bulk densities probably due to larger microcapsules formation with a more porous or fragmented structure as a result of the increased evaporation rate and droplet surface hardening at higher temperatures and MD concentrations [34, 38].

\subsection{Water solubility index and water absorption index}

Functional rehydration properties, WSI and WAI of powders are inversely proportional. Both, WSI and WAI of $S$. raeseri powders were significantly affected by the addition of MD. The highest WSI and the lowest WAI (86.40 and $5.71 \%$, respectively) were observed for powder obtained with $40 \% \mathrm{MD}$ at $120^{\circ} \mathrm{C}$. As shown in Table 2, the increase in MD concentration led to an increase in WSI and conversely, a decrease in WAI. Chegini and Ghobadian [28] attributed the variations in WSI and WAI caused by the increase in MD to its superior water solubility. Another reason behind the higher WSI with higher MD concentration may be due to the higher moisture content of powders [39]. The WSI of powders obtained by spray drying

Table 2 Water solubility index (WSI) and water apsorption index (WAI) of S. raeseri powders

\begin{tabular}{|c|c|c|c|c|c|}
\hline \multirow{3}{*}{ Carrier } & \multirow{3}{*}{ Carrier concentration } & \multicolumn{4}{|c|}{ Temperature $\left({ }^{\circ} \mathrm{C}\right)$} \\
\hline & & 120 & 140 & 120 & 140 \\
\hline & & \multicolumn{2}{|c|}{ WSI (\%) } & \multicolumn{2}{|c|}{ WAI (\%) } \\
\hline \multirow{4}{*}{ Maltodextrin } & 0 & $77.38 \pm 0.52^{\mathrm{a}}$ & $77.52 \pm 0.41^{\mathrm{a}}$ & $14.06 \pm 0.11^{\mathrm{a} 1}$ & $11.24 \pm 0.58^{\mathrm{a} 2}$ \\
\hline & 10 & $81.58 \pm 0.16^{\mathrm{b} 1}$ & $82.02 \pm 0.20^{\mathrm{b} 2}$ & $9.87 \pm 0.92^{b}$ & $9.78 \pm 0.24^{\mathrm{b}}$ \\
\hline & 20 & $84.53 \pm 0.21^{\mathrm{c}}$ & $85.47 \pm 0.84^{\mathrm{c}}$ & $7.41 \pm 0.25^{\mathrm{c}}$ & $7.04 \pm 0.91^{\mathrm{c}}$ \\
\hline & 40 & $86.40 \pm 0.65^{\mathrm{d} 1}$ & $79.16 \pm 0.25^{\mathrm{d} 2}$ & $5.71 \pm 0.25^{\mathrm{d} 1}$ & $8.01 \pm 0.33^{\mathrm{d} 2}$ \\
\hline Whey protein & 40 & $49.14 \pm 0.32^{\mathrm{e} 1}$ & $44.19 \pm 0.75^{\mathrm{e} 2}$ & $41.71 \pm 0.36^{\mathrm{e} 1}$ & $48.56 \pm 0.52^{\mathrm{e} 2}$ \\
\hline
\end{tabular}

Means followed by different letters $(\mathrm{a}, \mathrm{b}, \mathrm{c}, \mathrm{d})$ in a column are different from each other i.e., there is a significant and measurable difference between powders obtained with different carriers and concentrations at $p<0.05$ (the probability of obtaining that difference by chance is very small). This statistical parameter can therefore confirm the existence of powders with different competitive ability within the same property and process temperature. Means followed by the same letters within a column are not significantly different.

Means followed by different numbers $(1,2)$ in a row are different from each other, i.e., there is a significant difference between powders in terms of different properties and process temperature at $p<0.05$. This statistical parameter can therefore confirm the existence of powders with different competitive ability within the same carrier concentration. Means followed by the same number within a row are not significantly different. 
with MD differed significantly from that of WP powders. It was reported that $\mathrm{MD}$, as a result of its amorphous and noncrystalline character, may lead to higher solubility [40]. According to ANOVA, the WSI and WAI of some powders were significantly influenced by the different inlet temperatures. Lee et al. [39] and Phoungchandang and Sertwasana [15] reported a similar observation for WAI. Nadeem et al. [12] observed a more soluble S. stricta powder at higher inlet temperatures, whereas there are reports where a decrease of inlet temperature improved the water solubility and water absorption pointing to the need for the analysis of the powder microstructure [41].

\subsection{Particle size distribution}

Particle size is an important physical parameter relevant to powder stability, flowability, solubility, and bioactive retention. The particle size distribution of powders obtained under other process conditions exhibited similar behavior. Using WP as carrier did not create any observable particle variations in $S$. raeseri powders. The particles of $S$. raeseri powders were relatively uniform with their mean diameter from 4.13 to $5.79 \mu \mathrm{m}$. The particle size distribution was comparable to those of other formulations dried under similar process conditions [42, 43]. A significantly higher mean diameter was observed when the extract was spray-dried without MD at $140{ }^{\circ} \mathrm{C}(11.66 \mu \mathrm{m})$. According to da Silva Bastos et al. [44], a higher concentration of the feed solids could contribute to the increase in its viscosity and, consequently, in particle size during the atomization process. Larger particle size could also be correlated with higher hygroscopycity values that contributed to the stickiness of the drying particles and the beginning of the agglomeration process [45].
Particle size in spray-dried S. raeseri powders increased with higher inlet temperatures caused by the early formation of a dry surface layer on the droplet that does not allow the particle to shrink during spray drying, and is particularly common in skin-forming materials [28]. The opposite, but a statistically insignificant trend was noticed when 10 and 20\% MD was added. Sun et al. [43] reported that the particle size distribution of carvacrol powder was positively correlated with the inlet temperature increase from 100 to $190{ }^{\circ} \mathrm{C}$. Dadi et al. [46] stated that drying temperature also determined the particle size of Moringa stenopetala leaves powders, resulting in larger particles when higher temperature was applied $\left(120-160{ }^{\circ} \mathrm{C}\right)$.

\subsection{Total phenolic and flavonoid contents}

TPC and TFC of S. raeseri powders are presented in Table 3. According to the results, the spray-dried sample without the addition of carrier was characterized by the highest phenolic content. In addition, higher concentration of MD led to a lower TPC and TFC. This behavior is logical since the active material encapsulated in powder was diluted. The same trend of decrease in phenolics and flavonoids content was reported with the addition of MD in spray-dried S. stricta powder [12]. Vidović et al. [21] found that the increase of MD from 20 to $60 \%$ in encapsulated chokeberry dust decreased the TPC for $13.1-35.7 \%$. The lowest TPC and TFC were measured in WP powders which is in accordance with the data previously reported for persimmon pulp powder [47]. The authors emphasized the efficacy of MD over protein material, i.e., WP or egg albumin, to preserve phenolic compounds. Similarly, the addition of WP slightly decreased the TPC of black mulberry juice powder [48].

Table 3 The influence of inlet air temperature and carrier material concentration on total phenolic content (TPC) and total flavonoids content (TFC) of $S$.

\begin{tabular}{|c|c|c|c|c|c|}
\hline \multirow{3}{*}{ Carrier } & \multirow{3}{*}{ Carrier concentration } & \multicolumn{4}{|c|}{ Temperature $\left({ }^{\circ} \mathrm{C}\right)$} \\
\hline & & 120 & 140 & 120 & 140 \\
\hline & & \multicolumn{2}{|c|}{ TPC (mg GAE/g) } & \multicolumn{2}{|c|}{ TFC (mg CE/g) } \\
\hline \multirow{4}{*}{ Maltodextrin } & 0 & $29.92 \pm 0.10^{\mathrm{a} 1}$ & $24.87 \pm 0.13^{\mathrm{a} 2}$ & $35.43 \pm 0.66^{\mathrm{a} 1}$ & $23.82 \pm 0.28^{\mathrm{a} 2}$ \\
\hline & 10 & $26.55 \pm 0.34^{\mathrm{b}}$ & $26.10 \pm 0.48^{b}$ & $24.40 \pm 0.09^{\mathrm{b}}$ & $24.90 \pm 0.34^{\mathrm{a}}$ \\
\hline & 20 & $25.37 \pm 0.12^{\mathrm{c}}$ & $24.98 \pm 0.38^{\mathrm{ab}}$ & $31.78 \pm 0.16^{\mathrm{c} 1}$ & $30.49 \pm 0.15^{\mathrm{b} 2}$ \\
\hline & 40 & $21.33 \pm 0.21^{\mathrm{d} 1}$ & $22.56 \pm 0.59^{\mathrm{c} 2}$ & $24.68 \pm 0.27^{\mathrm{b} 1}$ & $20.89 \pm 0.38^{\mathrm{c} 2}$ \\
\hline Whey protein & 40 & $20.20 \pm 0.36^{\mathrm{e}}$ & $19.36 \pm 0.47^{\mathrm{d}}$ & $16.52 \pm 0.00^{\mathrm{d} 1}$ & $22.75 \pm 0.25^{\mathrm{d} 2}$ \\
\hline
\end{tabular}

*mg of gallic acid equivalents per $\mathrm{g}$ of powder; ** mg of catechin equivalents per $\mathrm{g}$ of powder.

Means followed by different letters (a, b, c, d) in a column are different from each other i.e., there is a significant and measurable difference between powders obtained with different carriers and concentrations at $p<0.05$ (the probability of obtaining that difference by chance is very small). This statistical parameter can therefore confirm the existence of powders with different competitive ability within the same property and process temperature. Means followed by the same letters within a column are not significantly different.

Means followed by different numbers $(1,2)$ in a row are different from each other, i.e., there is a significant difference between powders in terms of different properties and process temperature at $p<0.05$. This statistical parameter can therefore confirm the existence of powders with different competitive ability within the same carrier concentration. Means followed by the same number within a row are not significantly different. 
When analyzing the effect of the inlet temperature on the contents of phenolics and flavonoids, significant differences were observed in some cases. The higher inlet air temperature caused lower TPC and TFC probably as a result of alternation in the molecular structure of phenolics at higher temperature. These results are in agreement with a previous research studying the recovery of phenolic compounds from Emblica officinalis encapsulated with $5-9 \%$ MD using spray drying at $125-175{ }^{\circ} \mathrm{C}$ [49]. Bazaria and Kumar [34] stated that higher temperature decreased the TPC of beetroots powder while Sablania and Bosco [50] reported that intensifying inlet temperature $\left(140-180{ }^{\circ} \mathrm{C}\right)$ caused a loss in phenolics of Murraya koenigii powder. Other studies with comparable inlet temperature showed similar TPC/TFC, i.e., 16.14-37.68 mg GAE/g in cocoa bean shell powder [26], and 26.58-31.37 mg CE/g in white horehound [42]. Pljevljakušić et al. [18] reported similar results for the TPC of nonencapsulated $S$. raeseri extracts (15.3-34.1 mg GAE/g) indicating the protective effect of the encapsulation process.

\subsection{HPLC analysis}

HPLC analysis was performed for the quantification of flavonoid glycosides in $S$. raeseri powders, and the results are presented in Table 4. All powders contained 8-hydroxyflavone 7-allosylglucosides which are flavonoids characteristic of this species [8, 51]. Hypolaetin derivative (HYP 1) was the most abundant flavonoid glycoside in $S$. raeseri powders, followed by isoscutellarein derivatives (ISC 1 and ISC 2), whereas HYP 2 was present in the lowest amounts. It could be observed that the contents of flavonoids were reduced by the drying process, and the concentration of the encapsulant influenced the final flavonoid concentration in the powders. In all cases, the addition of different MD concentrations resulted in a decrease in flavonoids content. A lower concentration of MD was more efficient to entrap major flavonoid compounds, with loading capacity between $96 \%$ for ISC 1 and $99 \%$ for ISC 2 . By increasing the MD concentration up to $40 \%$, the ability of this carrier to protect flavonoids decreased to a $63-67 \%$ loading capacity. This finding follows the same trend previously presented for the total phenolic content (Table 3). The obtained results are in accordance with available literature data for S. stricta and sage extract where the loading capacity for total phenolics decreased with the increase of maltodextrin concentration $[19,12]$. WP in a concentration of $40 \%$ showed similar flavonoid entrapment (65-68\%) as MD with the same concentration. Belščak-Cvitanović et al. [52] also reported a $65 \%$ encapsulation efficiency of green tea polyphenols in whey protein powder. Additionally, the reason for a decrease in flavonoids glycosides concentration with the increase in the concentration of carriers can be the potential dilution effect.

The effect of different inlet temperatures on the flavonoid content was less pronounced than the impact of carrier concentration probably because applied temperatures were below the values where possible degradation of these compounds occurs. Different studies showed that temperatures higher than $160^{\circ} \mathrm{C}$ caused polymerization of phenolic compounds [53-55].

\section{Conclusions}

In the present work, it was demonstrated that the spray drying process can be successfully employed to obtain $S$. raeseri powders with optimal physico-chemical characteristics. In respect of the content of polyphenols and flavonoid glycosides in $S$. raeseri powder, it was determined that the addition of a carrier decreases the concentration of bioactive compounds in powders. However, when the efficiency of the process, quality parameters, and powder stability are taken into consideration, the addition of a carrier is necessary. The process of production of $S$. raeseri powder with the highest concentration of carriers was efficient

Table 4 Content of the individual flavonoid glycosides identified by HPLC-DAD in $S$. raeseri powders

\begin{tabular}{|c|c|c|c|c|c|c|c|c|c|}
\hline \multirow{3}{*}{ Carrier } & \multirow{3}{*}{$\begin{array}{c}\text { Carrier } \\
\text { concentration }\end{array}$} & \multicolumn{8}{|c|}{ Temperature $\left({ }^{\circ} \mathrm{C}\right)$} \\
\hline & & 120 & 140 & 120 & 140 & 120 & 140 & 120 & 140 \\
\hline & & \multicolumn{2}{|c|}{ ISC $1(\mathrm{mg} / \mathrm{g})$} & \multicolumn{2}{|c|}{ HYP 1 (mg/g) } & \multicolumn{2}{|c|}{ ISC $2(\mathrm{mg} / \mathrm{g})$} & \multicolumn{2}{|c|}{ HYP 2 (mg/g) } \\
\hline \multirow[t]{4}{*}{ Maltodextrin } & 0 & 28.31 & 27.91 & 32.94 & 32.52 & 30.41 & 30.10 & 2.34 & 2.32 \\
\hline & 10 & 27.22 & 25.28 & 32.26 & 29.61 & 30.09 & 27.45 & 1.96 & 2.06 \\
\hline & 20 & 22.39 & 24.17 & 26.72 & 28.65 & 24.86 & 26.65 & 1.54 & 1.64 \\
\hline & 40 & 17.96 & 17.61 & 22.11 & 23.76 & 20.56 & 22.87 & 1.49 & 0.68 \\
\hline Whey protein & 40 & 18.39 & 17.58 & 22.43 & 29.97 & 20.87 & 22.54 & 1.26 & 1.22 \\
\hline
\end{tabular}

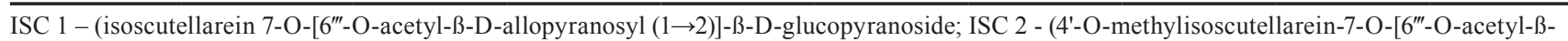
D-allopyranosyl $(1 \rightarrow 2)]-\beta-D$-glucopyranoside); HYP 1 - (4'-O-methylhypolaetin-7-O-[6"'-O-acetyl- 3 -D-allopyranosyl (1 $\rightarrow 2)]-\beta-D-$ glucopyranoside); HYP 2 - (4'-O-methylhypolaetin-7-O-[6"'-Oacetyl- $\beta-D$-allopyranosyl $(1 \rightarrow 2)]-6^{\prime \prime \prime}-O$-acetyl- $\beta$-D-glucopyranoside). 
at both inlet temperatures. MD demonstrated to be a more adequate carrier than WP for achieving a higher level of water solubility, low water absorption index, as well as low moisture content in powders. Higher temperature had a positive effect on the particle size distribution. In conclusion, spray-dried $S$. raeseri powder could be applied as a functional ingredient in food and pharmaceutical products based on its superior physicochemical properties.

\section{References}

[1] Gabrieli, C. N., Kefalas, P. G., Kokkalou, E. L. "Antioxidant activity of flavonoids from Sideritis raeseri", Journal of Ethnopharmacology, 96(3), pp. 423-428, 2005.

https://doi.org/10.1016/j.jep.2004.09.031

[2] Todorova, M., Trendafilova, A. "Sideritis scardica Griseb., an endemic species of Balkan peninsula: Traditional uses, cultivation, chemical composition, biological activity", Journal of Ethnopharmacology, 152(2), pp. 256-265, 2014.

https://doi.org/10.1016/j.jep.2014.01.022

[3] Aneva, I., Zhelev, P., Kozuharova, E., Danova, K., Nabavi, S. F., Behzad, S. "Genus Sideritis, section Empedoclia in southeastern Europe and Turkey - studies in ethnopharmacology and recent progress of biological activities", DARU Journal of Pharmaceutical Sciences, 27(1), pp. 407-421, 2019.

https://doi.org/10.1007/s40199-019-00261-8

[4] Obón de Castro, C., Rivera Núñez, D. "A taxonomic revision of the section Sideritis (Genus Sideritis) (Labiatae)", J. Cramer, Berlin, Germany, 1994.

[5] Stanoeva, J. P., Stefova, M., Stefkov, G., Kulevanova, S., Alipieva, K., Bankova, V., Aneva. I., Evstatieva, L. N. "Chemotaxonomic contribution to the Sideritis species dilemma on the Balkans", Biochemical Systematics and Ecology, 61, pp. 477-487, 2015.

https://doi.org/10.1016/j.bse.2015.07.008

[6] Brankovic, S., Kitic, D., Radenkovic, M., Veljkovic, S., Jankovic, T., Savikin, K., Zdunic, G. "Spasmolytic Activity of the Ethanol Extract of Sideritis raeseri spp. raeseri Boiss. \& Heldr. on the Isolated Rat Ileum Contractions", Journal of Medicinal Food, 14(5), pp. 495-498, 2011.

https://doi.org/10.1089/jmf.2010.0036

[7] Kitic, D., Brankovic, S., Radenkovic, M., Savikin, K., Zdunic, G., Kocic, B., Velickovic Radovanovic, R. "Hypotensive, vasorelaxant and cardiodepressant activities of the ethanol extract of Sideritis raeseri spp. raeseri Boiss \& Heldr", Journal of Physiology and Pharmacology, 63(5), pp. 531-535, 2012.

[8] Menković, N., Gođevac, D., Šavikin, K., Zdunić, G., Milosavljević, S., Bojadži, A., Avramoski, O. "Bioactive Compounds of Endemic Species Sideritis raeseri subsp raeseri Grown in National Park Galičica", Records of Natural Products, 7(3), pp. 161-168, 2013.

[9] Romanucci, V., Di Fabio, G., D'Alonzo, D., Guaragna, A., Scapagnini, G., Zarrelli, A. "Traditional uses, chemical composition and biological activities of Sideritis raeseri Boiss. \& Heldr.", Journal of the Science of Food and Agriculture, 97(2), pp. 373-383, 2017. https://doi.org/10.1002/jsfa.7867

\section{Acknowledgement}

The authors would like to thank Ana Jovanoski for her technical and editorial support. This research was funded by Serbian Ministry of Education and Science; Project No. 451-03-68/2020-14/200134.

[10] Desai, K. G. H., Jin Park, H. "Recent Developments in Microencapsulation of Food Ingredients", Drying Technology, 23(7), pp. 1361-1394, 2005.

https://doi.org/10.1081/DRT-200063478

[11] Gharsallaoui, A., Roudaut, G., Chambin, O., Voilley, A., Saurel, R. "Applications of spray-drying in microencapsulation of food ingredients: An overview", Food Research International, 40(9), pp. 1107-1121, 2007. https://doi.org/10.1016/j.foodres.2007.07.004

[12] Nadeem, H. Ş., Torun, M., Özdemir, F. "Spray drying of the mountain tea (Sideritis stricta) water extract by using different hydrocolloid carriers", LWT-Food Science and Technology, 44(7), pp. 1626-1635, 2011. https://doi.org/10.1016/j.1wt.2011.02.009

[13] Dontas, I. A., Lelovas, P. P., Kourkoulis, S. K., Aligiannis, N., Paliogianni, A., Mitakou, S., ..., N., Lyritis, G. P. "Protective effect of Sideritis euboea extract on bone mineral density and strength of ovariectomized rats", Menopause, 18(8), pp. 915-922, 2011. https://doi.org/10.1097/gme.0b013e31820ce580

[14] Vladić, J., Ambrus, R., Szabó-Révész, P., Vasić, A., Cvejin, A., Pavlić, B., Vidović, S. "Recycling of filter tea industry by-products: Production of $A$. millefolium powder using spray drying technique", Industrial Crops and Products, 80, pp. 197-206, 2016. https://doi.org/10.1016/j.indcrop.2015.11.085

[15] Phoungchandang, S., Sertwasana, A. "Spray-drying of ginger juice and physicochemical properties of ginger powders", Science Asia, 36(1), pp. 40-45, 2010.

https://doi.org/10.2306/scienceasia1513-1874.2010.36.040

[16] Kähkönen, M. P., Hopia, A. I., Vuorela, H. J., Rauha, J.-P., Pihlaja, K., Kujala, T. S., Heinonen, M. "Antioxidant Activity of Plant Extracts Containing Phenolic Compounds", Journal of Agricultural and Food Chemistry, 47(10), pp. 3954-3962, 1999. https://doi.org/10.1021/jf9901461

[17] Markham, K. R. "Techniques of Flavonoid Identification", Press, London, UK, 1982.

[18] Pljevljakušić, D., Šavikin, K., Janković, T., Zdunić, G., Ristić, M., Godjevac, D., Konić-Ristić, A. "Chemical properties of the cultivated Sideritis raeseri Boiss. \& Heldr. subsp. raeseri", Food Chemistry, 124(1), pp. 226-233, 2011. https://doi.org/10.1016/j.foodchem.2010.06.023

[19] Şahin-Nadeem, H., Dinçer, C., Torun, M., Topuz, A., Özdemir, F. "Influence of inlet air temperature and carrier material on the production of instant soluble sage (Salvia fruticosa Miller) by spray drying", LWT-Food Science and Technology, 52(1), pp. 31-38, 2013. https://doi.org/10.1016/j.lwt.2013.01.007 
[20] Do Carmo, E. L., Teodoro, R. A. R., Félix, P. H. C., de Barros Fernandes, R. V., de Oliveira, É. R., Veiga, T. R. L. A., Borges, S. V., Botrel, D. A. "Stability of spray-dried beetroot extract using oligosaccharides and whey proteins", Food Chemistry, 249, pp. 51-59, 2018.

https://doi.org/10.1016/j.foodchem.2017.12.076

[21] Vidović, S., Ramić, M., Ambrus, R., Vladić, J., Szabó-Révész, P., Gavarić, A. "Aronia Berry Processing by Spray Drying: From Byproduct to High Quality Functional Powder", Food Technology \&Biotechnology, 57(4), pp. 513-524, 2019. https://dx.doi.org/10.17113\%2Fftb.57.04.19.6369

[22] Balasubramani, P., Palaniswamy, P. T., Visvanathan, R., Thirupathi, V., Subbarayan, A., Prakash Maran, J. "Microencapsulation of garlic oleoresin using maltodextrin as wall material by spray drying technology", International Journal of Biological Macromolecules, 72, pp. 210-217, 2015.

https://doi.org/10.1016/j.ijbiomac.2014.08.011

[23] Bhandari, B. R., Datta, N., Howes, T. "Problems Associated with Spray Drying of Sugar-Rich Foods", Drying Technology, 15(2), pp. 671-684, 1997.

https://doi.org/10.1080/07373939708917253

[24] Sun, X., Cameron, R. G., Bai, J. "Microencapsulation and antimicrobial activity of carvacrol in a pectin-alginate matrix", Food Hydrocolloids, 92, pp. 69-73, 2019. https://doi.org/10.1016/j.foodhyd.2019.01.006

[25] Adhikari, B., Howes, T., Bhandari, B. R., Langrish, T. A. G. "Effect of addition of proteins on the production of amorphous sucrose powder through spray drying", Journal of Food Engineering, 94(2), pp. 144-153, 2009.

https://doi.org/10.1016/j.jfoodeng.2009.01.029

[26] Jokić, S., Nastić, N., Vidović, S., Flanjak, I., Aladić, K., Vladić, J. "An Approach to Value Cocoa Bean By-Product Based on Subcritical Water Extraction and Spray Drying Using Different Carriers", Sustainability, 12(6), Article number: 2174, 2020. https://doi.org/10.3390/su12062174

[27] Ståhl, K., Claesson, M., Lilliehorn, P., Lindén, H., Bäckström, K. "The effect of process variables on the degradation and physical properties of spray dried insulin intended for inhalation", International Journal of Pharmaceutics, 233(1-2), pp. 227-237, 2002. https://doi.org/10.1016/s0378-5173(01)00945-0

[28] Chegini, G. R., Ghobadian, B. "Effect of Spray-Drying Conditions on Physical Properties of Orange Juice Powder", Drying Technology, 23(3), pp. 657-668, 2005. https://doi.org/10.1081/DRT-200054161

[29] Phisut, N. "Spray drying technique of fruit juice powder: some factors influencing the properties of product", International Food Research Journal, 19(4), pp. 1297-1306, 2012.

[30] Pisecky, J. "Handbook of Milk Powder Manufacture", GEA Process Engineering A/S, Copenhagen, Denmark, 2012. [online] Available at: https://www.gea.com/en/expert-knowledge/milkpowder-manufacture/index.jsp [Accessed: 27 March 2020]

[31] Sansone, F., Mencherini, T., Picerno, P., d'Amore, M., Aquino, R. P., Lauro, M. R. "Maltodextrin/pectin microparticles by spray drying as carrier for nutraceutical extracts", Journal of Food Engineering, 105(3), pp. 468-476, 2011. https://doi.org/10.1016/j.jfoodeng.2011.03.004
[32] Quek, S. Y., Chok, N. K., Swedlund, P. "The physicochemical properties of spray-dried watermelon powders", Chemical Engineering and Processing: Process Intensification, 46(5), pp. 386-392, 2007. https://doi.org/10.1016/j.cep.2006.06.020

[33] Tonon, R. V., Brabet, C., Hubinger, M. D. "Influence of process conditions on the physicochemical properties of açai (Euterpe oleraceae Mart.) powder produced by spray drying", Journal of Food Engineering, 88(3), pp. 411-418, 2008. https://doi.org/10.1016/j.jfoodeng.2008.02.029

[34] Bazaria, B., Kumar, P. "Effect of whey protein concentrate as drying aid and drying parameters on physicochemical and functional properties of spray dried beetroot juice concentrate", Food Bioscience, 14, pp. 21-27, 2016. https://doi.org/10.1016/j.fbio.2015.11.002

[35] Sablani, S. S., Shrestha, A. K., Bhandari, B. R. "A new method of producing date powder granules: Physicochemical characteristics of powder", Journal of Food Engineering, 87(3), pp. 416-421, 2008. https://doi.org/10.1016/j.jfoodeng.2007.12.024

[36] Tonon, R. V., Brabet, C., Hubinger, M. D. "Anthocyanin stability and antioxidant activity of spray-dried açai (Euterpe oleracea Mart.) juice produced with different carrier agents", Food Research International, 43(3), pp. 907-914, 2010. https://doi.org/10.1016/j.foodres.2009.12.013

[37] Manickavasagan, A., Thangavel, K., Dev, S. R. S., Aniesrani Delfiya, D., Nambi, E., Orsat, V., Raghavan, G. S. V. "Physicochemical Characteristics of Date Powder Produced in a Pilot-Scale Spray Dryer", Drying Technology, 33(9), pp. 1114-1123, 2015. https://doi.org/10.1080/07373937.2015.1014045

[38] Jumah, R. Y., Tashtoush, B., Shaker, R. R., Zraiy, A. F. "Manufacturing parameters and quality characteristics of spray dried jameed", Drying Technology, 18(4-5), pp. 967-984, 2000. https://doi.org/10.1080/07373930008917747

[39] Lee, K.-C., Yoon, Y. S., Li, F.-Z., Eun, J.-B. "Effects of inlet air temperature and concentration of carrier agents on physicochemical properties, sensory evaluation of spray-dried mandarin (Citrus unshiu) beverage powder", Applied Biological Chemistry, 60(1), pp. 33-40, 2017. https://doi.org/10.1007/s13765-016-0246-8

[40] Santhalakshmy, S., Bosco, S. J. D., Francis, S., Sabeena, M. "Effect of inlet temperature on physicochemical properties of spray-dried jamun fruit juice powder", Powder Technology, 274, pp. 37-43, 2015.

https://doi.org/10.1016/j.powtec.2015.01.016

[41] Rubel, I. A., Iraporda, C., Novosad, R., Cabrera, F. A., Genovese, D. B., Manrique, G. D. "Inulin rich carbohydrates extraction from Jerusalem artichoke (Helianthus tuberosus L.) tubers and application of different drying methods", Food Research International, 103, pp. 226-233, 2018. https://doi.org/10.1016/j.foodres.2017.10.041

[42] Gavarić, A., Vladić, J., Ambrus, R., Jokić, S., Szabó-Révész, P., Tomić, M., Blažić, M., Vidović, S. "Spray Drying of a Subcritical Extract Using Marrubium vulgare as a Method of Choice for Obtaining High Quality Powder", Pharmaceutics, 11(10), Article number: 523, 2019.

https://doi.org/10.3390/pharmaceutics11100523 
[43] Sun, X., Cameron, R. G., Bai, J. "Effect of spray-drying temperature on physicochemical, antioxidant and antimicrobial properties of pectin/sodium alginate microencapsulated carvacrol", Food Hydrocolloids, 100, Article number: 105420, 2020. https://oi.org/10.1016/j.foodhyd.2019.105420

[44] da Silva Bastos, D., do Pilar Gonçalves, M., de Andrade, C. T., de Lima Araújo, K. G., da Rocha Leão, M. H. M. "Microencapsulation of cashew apple (Anacardium occidentale L.) juice using a new chitosan-commercial bovine whey protein isolate system in spray drying", Food and Bioproducts Processing, 90(4), pp. 683-692, 2012. https://doi.org/10.1016/j.fbp.2012.04.005

[45] Both, E. M., Boom, R. M., Schutyser, M. A. I. "Particle morphology and powder properties during spray drying of maltodextrin and whey protein mixtures", Powder Technology, 363, pp. 519-524, 2020. https://doi.org/10.1016/j.powtec.2020.01.001

[46] Dadi, D. W., Emire, S. A., Hagos, A. D., Eun, J.-B. "Effects of spray drying process parameters on the physical properties and digestibility of the microencapsulated product from Moringa stenopetala leaves extract", Cogent Food \& Agriculture, 5(1), Article number: 1690316, 2019. https://doi.org/10.1080/23311932.2019.1690316

[47] Du, J., Ge, Z.-Z., Xu, Z., Zou, B., Zhang, Y., Li, C.-M. "Comparison of the Efficiency of Five Different Drying Carriers on the Spray Drying of Persimmon Pulp Powders", Drying Technology, 32(10), pp. 1157-1166, 2014. https://doi.org/10.1080/07373937.2014.886259

[48] Wang, R., Zhao, Y., Zhu, L., Fang, Z., Shi, Q. "Effect of carrier types on the physicochemical and antioxidant properties of spraydried black mulberry juice powders", Journal of Food Measurement and Characterization, 14(3), pp. 1201-1212, 2020. https://doi.org/10.1007/s11694-019-00369-0

[49] Mishra, P., Mishra, S., Mahanta, C. L. "Effect of maltodextrin concentration and inlet temperature during spray drying on physicochemical and antioxidant properties of amla (Emblica officinalis) juice powder", Food and Bioproducts Processing, 92(3), pp. 252-258, 2014.

https://dx.doi.org/10.1016/j.fbp.2013.08.003
[50] Sablania, V., Bosco, S. J. D. "Optimization of spray drying parameters for Murraya koenigii (Linn) leaves extract using response surface methodology", Powder Technology, 335, pp. 35-41, 2018. https://doi.org/10.1016/j.powtec.2018.05.009

[51] Petreska, J., Stefova, M., Ferreres, F., Moreno, D. A., TomásBarberán, F. A., Stefkov, G., Kulevanova, S., Gil-Izquierdo, A. "Potential bioactive phenolics of Macedonian Sideritis species used for medicinal 'Mountain Tea'", Food Chemistry, 125(1), pp. 13-20, 2011. http://dx.doi.org/10.1016\%2Fj.foodchem.2010.08.019

[52] Belščak-Cvitanović, A., Lević, S., Kalušević, A., Špoljarić, I., Đorđević, V., Komes, D., Nedović, V. "Efficiency Assessment of Natural Biopolymers as Encapsulants of Green Tea (Camellia sinensis L.) Bioactive Compounds by Spray Drying", Food and Bioprocess Technology, 8(12), pp. 2444-2460, 2015. https://doi.org/10.1007/s11947-015-1592-y

[53] Ersus, S., Yurdagel, U. "Microencapsulation of anthocyanin pigments of black carrot (Daucus carota L.) by spray drier", Journal of Food Engineering, 80(3), pp. 805-812, 2007. https://doi.org/10.1016/j.jfoodeng.2006.07.009

[54] Fang, Z., Bhandari, B. "Effect of spray drying and storage on the stability of bayberry polyphenols", Food Chemistry, 129(3), pp. 1139-1147, 2011. https://doi.org/10.1016/j.foodchem.2011.05.093

[55] Tolun, A., Altintas, Z., Artik, N. "Microencapsulation of grape polyphenols using maltodextrin and gum arabic as two alternative coating materials: Development and characterization", Journal of Biotechnology, 239, pp. 23-33, 2016. https://doi.org/10.1016/j.jbiotec.2016.10.001 